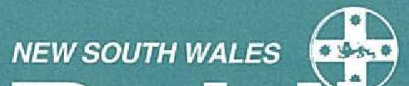 Public Health Bulletin
}

\section{Program BUDGetING AND MARGINAL ANALYSIS: A GUIDE TO RESOURCE ALLOCATION}

Rosalie Viney, Marion Haas and Gavin Mooney

Centre for Health Economics Research \& Evaluation

Westmead Hospital

$\mathrm{n}$ this paper we explain how program budgeting and marginal analysis (PBMA) can be used to assist decisions about resource allocation at a local level, leading to improvements in the health of the population. We review overseas experience with PBMA and outline a proposed application of PBMA in NSW.

The focus of health services in NSW has shifted from efficiency defined in terms of outputs to maximising health outcomes. The purpose of the health system is to deliver better health rather than more health services, and goals and targets for improving health are being determined for the main health problem areas. If the vision of a health system oriented towards achieving the best possible health for the people of NSW is to be fulfilled, shifts of resources will have to occur. For improvements in health outcomes to become the main focus of the system at all levels, it must be recognised that changes will be achieved through marginal shifts rather than revolutions. To achieve this, appropriate incentives must be provided. Better health is a longterm outcome, so success will have to be measured in the shorter term by monitoring intermediate objectives for which there is evidence of a relationship to improved health.

\section{WHAT IS PBMA?}

Program budgeting involves dividing the health services in a geographical area, hospital or clinical unit into a set of programs. These programs must have clear health-related objectives. They may, for example, be based on particular disease groups or specific client groups.

The best available data are then used to estimate the resource costs and outputs for each program. Outputs should be quantified in terms of readily available measures, for example numbers of patients treated or numbers of visits. This step should be carried out across different programs and within each program. Program budgeting, therefore, provides a means to determine how much is being spent and the outputs achieved. It is intended only to provide the framework for evaluation and does not make a direct evaluation itself.

Marginal analysis forms the basis of the evaluation of the programs.

\section{Contents}

\section{Articles}

29 Program budgeting and marginal analysis: a guide to resource allocation

31 Unusual fox behaviour: rabies exclusion investigation

\section{Public Health Abstracts}

\section{Infectious Diseases}

\section{Notifications}

\section{Correspondence}

Please address all correspondence and potential contributions to:

The Editor,

NSW Public Health Bulletin, Public Health Division, NSW Health Department Locked Bag No 961, North Sydney NSW 2059 Telephone: (O2) 3919191 Facsimile: (02) 3919029 


\section{Program budgeting and marginal analysis}

Continued from page 29

It can be applied to the programs overall, or within each program at the subprogram level. Marginal analysis provides a means to determine what benefits would be lost and what benefits gained if a given amount of resources were to be shifted from one program to another (or, within a program, from one subprogram to another). Are the benefits gained greater than the benefits forgone? For example, if $\$ 100,000$ were shifted from outpatient aged care services to aged care assessment, what benefits would be lost from outpatient care and what benefits would be gained in assessment? The answers to these questions provide an objective basis for deciding whether the resource shift is worthwhile.

The process of marginal analysis would be straightforward if all benefits could be measured in the same units of "health gain". Although this is not generally possible, marginal analysis can be undertaken with whatever information is available. The most important aspect is the process of explicit comparison of costs and benefits, giving the decision maker as much information as possible about the relative sizes of gains and losses.

The concepts underlying PBMA are simple. If less spending on one program frees resources which yield more benefits elsewhere than those which are forgone, there is a strong argument for shifting the resources. PBMA addresses the issue of allocation efficiency - i.e. maximising benefits with available resources. So far, the health system has made progress in addressing technical efficiency -i.e. how to produce a given output at lowest cost. However, managers must also focus on the question of which outputs to produce, and in what quantities. PBMA provides a mechanism for identifying the costs and benefits of expanding and contracting different services.

In addition, PBMA provides a mechanism whereby the trade-off between efficiency and equity objectives can be made explicit. The costs and benefits of particular proposals in terms of both health gain and, for example, equity of access, can be estimated and taken into account in decision making. However, this requires the equity objectives to be made explicit.

In an ideal world good information about the costs and outcomes of programs would be brought together to establish how to maximise health benefits with the available resources. In the real world, good data are often unavailable, and PBMA can be applied with whatever information is available. Routinely available cost and output information can be used but it is important to determine the relationship between routinely available measures and health gain (for example, from published studies).

\section{PBMA IN PRACTICE}

PBMA was first suggested as an approach to priority setting in health in the $1970 \mathrm{~s}$, with one of the earliest applications being in the Grampian region in Scotland ${ }^{1,2,3}$. It was also used by the UK Department of Health in London to assist in priority setting in the late 1970s. With the development of a focus on health outcomes internationally, there has been a resurgence of interest in PBMA. It is now being used by several health authorities in the UK (including Grampian, Teeside, Liverpool and - as described below - in Mid Glamorgan, Wales) $^{4,5}$ and in New Zealand (Midland Regional Health Authority). The New Zealand Ministry of Health has also recently recommended the use of PBMA by Regional Health Authorities. These initiatives are at different stages, but it is clear that the implementation of PBMA is complicated by factors such as rationalisation of services, overall resource constraints and population shifts. The UK experience of PBMA was comprehensively reviewed at a conference, the proceedings of which will appear in a special issue of Health Policy in 1995.

A pilot implementation of PBMA carried out on maternal and early child health services in the Mid Glamorgan District Health Authority was recently reported ${ }^{5}$. This example is particularly relevant to NSW because the focus on health gain in Wales has parallels with that in NSW. In Wales, areas of health gain had been defined and objectives established, and several districts had already produced program budgets defined for these areas. In the pilot, an expert group prepared 10 proposals for increasing resource allocation and 10 for decreasing resource allocation. It was emphasised that decreasing funding did not imply that the current allocation was excessive, but rather identified those activities which might be considered if reductions were to be made. The second stage involved applying economic analysis to estimate the net gains that would result if $£ 100,000$ were shifted from the areas of decreased funding to each area of increased investment. Criteria were established to evaluate the benefits in each instance. This stage is important because it recognises that efficiency is not the only objective.

Out of this process five proposals for investment and five for decreased funding were agreed, and are being implemented. As an example, one proposal for expansion was the identification of, and targeted support for, women with high-risk pregnancies, and one proposal for decreased funding was "number of ear, nose and throat operations of questionable benefit and length of stay" .

The overseas experience has showed that PBMA is "not only attractive in theory but useful in practice" ${ }^{n}$, and several lessons follow from it:

- PBMA is likely to prove most successful in an environment and policy framework which supports it, such as in Wales; 


\section{Program budgeting and marginal analysis}

$\checkmark$ Continued from page 30

- the difficult stage of the process is marginal analysis, and it must be recognised that this takes time; the composition of the PBMA working groups needs careful attention, but the overseas experience suggests they should be multidisciplinary; marginal analysis involves value judgments which are dependent on local knowledge, and therefore it must be implemented locally; PBMA is dependent on preparedness to consider and then carry through the identified resource shifts; and there seems to be no rational alternatives which will allow an approach to efficiency based largely on existing data.

\section{PBMA IN NSW}

PBMA is being developed as an element of the outcomes approach in NSW. The Centre for Health Economics Research \& Evaluation (CHERE) is working with the NSW Health Department's Policy and Planning Division to establish and evaluate pilot projects over the next 12 months. During 1995 CHERE will run a series of workshops for health service planners and managers on how to implement PBMA, and meetings with Area and District Health Services' Health Outcomes Councils to identify possible projects. In addition, PBMA is proposed as part of the implementation of an approach to improve outcomes for people with diabetes.

In this context it will be important to identify the respective roles of Statewide and Area or District services. For PBMA to be successful, clear State objectives must guide priority setting, and information about effective interventions must be readily available. This is best coordinated at a Statewide level. Although the process is not data driven, a Statewide data system and casemix information could be useful in assisting Areas and Districts in establishing program budgets. Decisions about the final structure of the programs, establishing goals, supplementing information on outputs and resources and undertaking marginal analysis and resource shifts are the province of Areas and Districts. Although PBMA may be time-consuming and difficult, the process can help to ensure that prioritysetting decisions are based on objective criteria.

1. Mooney GH. Programme budgeting in an Area Health Board. HERU discussion paper No 01/77, 1977.

2. Mooney GH. Planning for balance of care of the elderly. Scottish Journal of Political Economy 1978; 25:149-164.

3. Mooney G, Russell EM and Weir RD. Choices for health care. London: Macmillan, 1986.

4. Shiell A, Hall J, Jan S and Seymour J. Advancing health in New South Wales: planning in an economic framework. CHERE discussion paper No 23, 1993.

5. Cohen D. Marginal analysis in practice: an alternative to needs assessment for contracting health care. Br Med J 1994; 309:781-4.

\section{Public health abstractS}

Drofessor James S. Lawson, Professor and Head of the School of Health Services Management at the University of NSW, has prepared the following public health items from the literature.

\section{REDUCING FALLS IN THE ELDERLY}

Falling is a serious public health problem among elderly people because of its frequency, the morbidity associated with falls and the cost of necessary health care. In a prospective trial in the US, elderly subjects had a range of interventions, including modification of medications, removal of hazards, and appropriate physical exercise. During the year of follow-up 35 per cent of the intervention group had falls, compared with 47 per cent of the control group.

Tinetti ME, Baker DI, McAvay G et al. A multifactorial intervention to reduce the risk of falling among elderly people living in the community. N Engl J Med 1994; 331:821-827.

\section{DOMESTIC VIOLENCE DURING PREGNANCY}

A survey of pregnant women attending the Royal Women's Hospital in Brisbane has shown that 5.8 per cent had been abused. One-third sought medical treatment as a consequence of the abuse. The injuries included lacerations, bruising and gynaecological damage. Because most women will not reveal details of violence in the home unless asked, it is recommended that a relationship history should be included at the first visit with medical, obstetric and other histories.

Webster J, Sweett S, Stoltz TA. Domestic violence in pregnancy. Med J Aust 1994; 161:466-470.

\section{ACCURACY OF WEIGHING INFANTS}

The weighing of infants at Early Childhood Centres is a major preventive health activity. A Queensland study has demonstrated that due to normal physiological variations infants' mass can vary by as much as 3 per cent. Staff and parents should be made aware of this and should not become concerned with what are normal variations.

Alsop-Shields IE, Alexander HG, Dugdale AE. The accuracy of weighing infants. Med J Aust 1994; 161:489-490.

\section{MALARIA VACCINES: THE SEARCH GOES ON}

The journey to an effective vaccine against malaria has been long, tough and expensive. The major "breakthrough" was that of Pattaroyo et al in Colombia. This vaccine can prevent more than 30 per cent of infections in South America. The first results of trials in Africa have been reported. This was a tough test because malaria in parts of Africa is a universal infection, i.e. all the members of some populations are infected. The early results are encouraging in that protection at about 30 per cent is similar to Colombia. This does not seem so good compared with other vaccines, but it is the best attained with malaria.

White NJ. Tough test for malaria vaccine. Lancet 1994; 1172-1173. 